\title{
Modelling of Multi-Mitigation Strategies for Maritime Disruptions in the Wheat Supply Chain
}

\author{
Saut Gurning 1 - Stephen Cahoon ${ }^{2},{ }^{*}$ - Branislav Dragovic ${ }^{3}$ - Hong-Oanh Nguyen ${ }^{2}$ \\ 1 Sepuluh Nopember Institute of Technology, Indonesia \\ 2 University of Tasmania, Australian Maritime College, Australia \\ 3 University of Montenegro, Maritime Faculty, Montenegro
}

\begin{abstract}
This paper assesses potential mitigation strategies for maritime disruptions occurring during the containerised transport of wheat in wheat supply chains (WSC). The assessment focuses on four major mitigation strategies (inventory and sourcing mitigation, contingency rerouting, recovery planning, and business continuity planning) in order to determine their suitability for managing potential disruptions in the WSC. In this paper, a Markovian-based methodology is the prime means used to evaluate the WSC mitigation strategies. The results of the continuous time period of the Markov chain application suggest that optimised mitigation strategies include the measurement and prediction of WSC costs and time functions over a one-year period.
\end{abstract}

Keywords: containerised wheat supply chains, multi-mitigation strategies modelling, maritime disruptions

\section{O INTRODUCTION}

There is a variety of operations involved in loading and transporting a container of wheat. One method is to base the process on the existing system used by wheat-grade producers or farmers: wheat is harvested, then cleaned, separated (by size or other characteristics), graded, and bagged either on the farm or at a nearby facility. The bags of wheat are then stockpiled in a warehouse or shipped directly via containers to the facility. During the shipping of containerised wheat, changes in the performance of wheat supply chains (WSC) may be identified beyond the assumptions predicted in a generic planning stage. These changes include factors such as changing demand, the origin of supply sources, distances, and lead times, all which may fluctuate widely resulting in a variety of at times, unexpected transportation costs. Supply chain optimisation models have traditionally treated the WSC with certainty and frequently ignore unpredicted events such as disruptions and disasters (for example [1]). In reality, operational parameter estimations may be inaccurate due to poor forecasts, measurement errors, changing demand patterns of the wheat commodity, inadequate sea transport infrastructure and managerial problems, all of which may vary substantially depending on the destination of the wheat. Moreover, even if all the variables of the WSC could be known with certainty, only some may be identified as causing disruptions. A major cause of disruptions tends to stem from the maritime leg of the WSC; for example, in the case of wheat and its derivative products, these may be inclement weather, sea terminal congestion, the requirements imposed by agencies within the marketing systems and a shortage in the dry-bulk fleet [2]. Therefore, significant attention to potential maritime disruptions in a WSC is required, particularly as the wheat industry is more vertically integrated than in the past, and its supply chains are increasingly global, thus often necessitating a maritime segment [3].

In contrast, in [4], the lot size optimisation problem in supply chain management is solved using the artificial neural networks method. An integrated protocol for research and development-marketing integration, based on the theoretical framework for new product development is considered in [5]. An intelligent decision support system for the design process is developed in [6]. In [7], a combined method of a simulated annealing algorithm and the best priority rules for solving the problem of scheduling in multi-projects is presented.

The objective of this paper is to provide a mitigation framework for both maritime service operators and users that can respond to various maritime disruptive events when managing a containerised WSC. This paper applies a maritime disruption model constructed for use in an AustralianIndonesian WSC context, which incorporates a WSC simulation, available data, and judgments from practitioners in order to quantify a disruption level arising from the contribution of situational attributes to maritime disruptions.

The rest of the paper is organised as follows. The problem statement and maritime disruption strategies in a WSC are discussed in Section 2. Section 3 presents the mathematical model, followed by the Australia-Indonesia WSC computational experiments in Section 4. Conclusions are presented in Section 5. 


\section{PROBLEM STATEMENT AND MARITIME DISRUPTION IN A WHEAT SUPPLY CHAIN}

\subsection{The Stages of Maritime Disruption}

Understanding the stages of disruptive maritime events in the broad perspective of a WSC operation can be derived from the general logical approach of a common disruption framework. In general terms, some studies describe the stages of a disruption risk by the operational outcomes of disruptions and their effects on supply chain performance [8]. In terms of the scale of disruptions, these stages may experience a recurrent risk of individual events, ranging from delays to disaster events that demolish the service platform of a supply chain [9]. In total, there are four stages of disruption: delay, deviation, stoppages, and the loss of the service platform.

The delay stage is the first stage through which a maritime risk passes. During this stage, the focus is on the recurrent changes in the performance of a service operation in the supply chain resulting in the cancelation of pre-determined planning by managers. During the deviation stage, planners of a service operation need to re-evaluate their external and internal service plan to account for the more significant changes to current operations resulting in forecasted objectives and service levels not being attained. The reduced level of operations can be contrasted against the stoppages stage, in which some existing services become unavailable due to direct and indirect factors interrupting the services' provisions. The final stage is the loss of service platform, whereby the service platform is damaged, and as a consequence, service operators in the supply chain are unable to provide their services for a substantially longer period than in the third stage. The end result may be the continued unavailability of transport facilities and the shutting down of particular service points in the supply chain [10].

Within the four stages are events that may trigger maritime disruptions. These causal factors are referred to here as stimulators [11]. Potential stimulators include security threats, political riots or wars, lack of facilities and management at ports, lengthy customs and quarantine processes, severe weather conditions and earthquakes, electrical outages, a lack of maintenance, a shortage of ships, an insufficient number of empty containers, uncertainty of bunkering costs, communication failures, and a lack of inland accessibility [12] and [13].

The outcomes of a delay, deviation, stoppage, and/ or loss of service platform may generate unavoidable divergences from the original plans of supply chain operations. In addition, those outcomes may also be regarded as stages through which disruptions evolve, starting from a delay to the loss of service platform or a disaster when unwanted internal or external changes occur in a supply chain.

\subsection{A Review of Maritime Disruption Strategies}

The goal of mitigating maritime disruptions in the WSC is to alleviate the consequences of disruptions and risks or, simply put, to increase the robustness of a WSC through the maritime leg. However, there is little evidence of qualitative approaches being used to mitigate maritime disruptions, particularly during specific periods such as pre-disruption, at time disruption, and post-disruption.

For example, the majority of supply disruption papers (as shown in Table 1 [12]) focus on the combination of contingency rerouting and inventory/ sourcing mitigation strategies in response to maritime disruptions. The research further finds that the dominant approaches by maritime users in managing the WSC during a disruptive event is to adapt to a new route on the maritime leg, use strategic stock (when no alternative source is available), utilise backup systems, and/or to implement business continuity actions (see Table 1).

Table 1. Mitigation strategies for a WSC

\begin{tabular}{|c|c|c|}
\hline Mitigation & Strategies & Literature \\
\hline \multirow{6}{*}{$\begin{array}{l}\text { Inventory and } \\
\text { Sourcing }\end{array}$} & Inventory polling at ports & [2] \\
\hline & Utilising agency service & [14] \\
\hline & Apply other chain links & [15] \\
\hline & Optimum ordering policy & [14] \\
\hline & Postponement delays & [16] \\
\hline & Supply flexibility & [17] \\
\hline \multirow{4}{*}{$\begin{array}{l}\text { Contingency } \\
\text { Rerouting }\end{array}$} & Reserves routes & [16] \\
\hline & Critical nodes mapping & [9] \\
\hline & Applies other chain links & [3] \\
\hline & Formal assessment & [18] \\
\hline \multirow{4}{*}{$\begin{array}{l}\text { Business } \\
\text { Continuity } \\
\text { Planning }\end{array}$} & Changes to work practices & [19] \\
\hline & Max. allowable interruption & [20] \\
\hline & Develop warning system & [9] \\
\hline & Risk impact monitoring & [21] \\
\hline \multirow{3}{*}{$\begin{array}{l}\text { Recovery } \\
\text { Planning }\end{array}$} & Apply discovery responses & [22] \\
\hline & Apply recovery actions & [22] \\
\hline & Network \& proc. redesign & [23] \\
\hline
\end{tabular}

Choices such as inventory pooling at ports, changes to working practices, applying other chain links, postponement delays, formal assessment of risk, determining the maximum allowable interruption, risk 


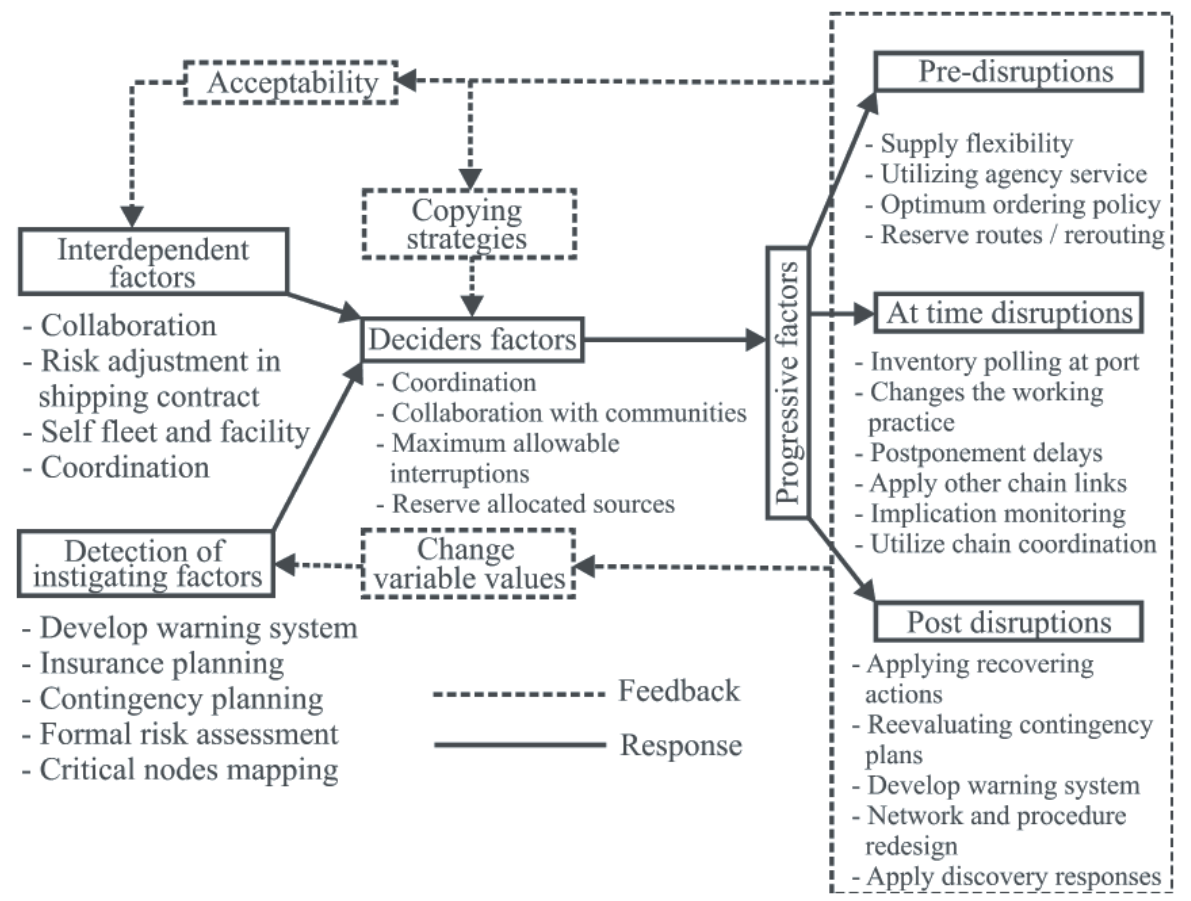

Fig. 1. A framework for maritime disruption strategies

impact monitoring, and re-evaluating contingency plans are considered as strategies that occur in the postdisruption stage. These choices, including constraints, are assessed in the context of five different maritime consequences as conditional events, such as normal, delays, deviation, stoppages, and loss of port services. Any input data included in calculating parametric variables may vary between scenario objectives. However, the way in which parametric variables are calculated from historical data and the way they are applied in the estimating process should be consistent within individual estimating systems. Input data was gathered from a maritime disruption survey which was collected both quantitatively and qualitatively and combined with the triangulation method. Fig. 1 shows a framework of maritime disruption strategies that was developed from the literature, which also reflects information from the maritime disruption survey and scenario assessments at various observations of maritime disruptive events [24].

The assessment of a maritime disruption management scenario comprises a component expressing the preparedness and strategic choices in the three stages of disruption: pre-disruption, at-time disruption and post-disruption [9], [12], [15] and [17]. The assessments specify the decision framework of senior managers' action choices, such as changing variable values, copying strategies, or accepting or continuing the previous actions. However, the performance is also dependent on instigating factors, inter-dependent factors and the combination of both as decider factors [9] and [23].

The above strategies appear to be the common steps in disruption risk management and contingency planning addressed by the literature (Table 1); however, these strategies tend not to consider the sequence of maritime disruptions that occur before, during, and after the disruption. The current study therefore differs in that it explores the optimised strategies during the various stages of maritime disruptions by applying qualitative and quantitative approaches to managing the delay, deviation, stop, and loss as consequences occurring during the sequence of maritime disruptions.

Quantitative and qualitative input data were gathered from a maritime disruption survey in 2009/2010 from senior managers involved in the Australian-Indonesian WSC and triangulated with findings from previous studies to provide scenario assessments at various observations of maritime disruptive events (see Table 2).

There are 16 disruption management scenarios listed in Table 2, all of which have ranges of costs attached to them. For example, $\mathrm{S}_{11}$ is the cost using inventory pooling ports $(i=1)$ for a delay risk $(j=$ 1). The ranges of costs from $S_{11}$ to $S_{416}$ exist across all entities in the Australian-Indonesian WSC. The disruption management scenarios that can 
be applied by senior managers when maritime disruptions occur are inventory pooling, agency utilisation, using other chain links, applying optimum ordering, postponing delays, using supply flexibility strategies, using reserved routes, mapping out the critical nodes, containerised shipment (as one of the business continuity responses), changing work practices, enabling allowable interruptions, applying warning systems, using implication monitoring, and developing an insurance package. In addition, senior managers can also set up a risk preparedness strategy or contingencies for operations management in both countries, which are used to detect and reduce the potential for maritime disruptions or commercial issues between sellers and buyers [25].

Table 2. The i-scenarios of disruption management and j-consequences indicators

\begin{tabular}{|c|c|c|c|c|c|}
\hline \multirow{2}{*}{$\begin{array}{c}\text { Scenario } \\
i\end{array}$} & \multirow{2}{*}{ Type of DMS } & \multicolumn{4}{|c|}{ Consequences indicators } \\
\hline & & $\mathrm{J}=1$ & $\mathrm{~J}=2$ & $\mathrm{~J}=3$ & $\mathrm{~J}=4$ \\
\hline$i=1$ & Inventory pooling ports & S11 & S21 & S31 & S41 \\
\hline$i=2$ & Utilising agency service & S12 & S22 & S32 & S42 \\
\hline$i=3$ & Control access to load & S13 & S23 & S33 & S43 \\
\hline$i=4$ & $\begin{array}{l}\text { Optimum ordering } \\
\text { policy }\end{array}$ & S14 & S24 & S34 & S44 \\
\hline$i=5$ & Postponement delays & S15 & S25 & S35 & S45 \\
\hline$i=6$ & Supply flexibility & S16 & S26 & S36 & S46 \\
\hline$i=7$ & Reserves routes & $\mathrm{S} 17$ & S27 & S37 & S47 \\
\hline$i=8$ & Critical nodes mapping & S18 & S28 & S38 & S48 \\
\hline$i=9$ & Apply other chain links & S19 & S29 & S39 & S49 \\
\hline$i=10$ & $\begin{array}{l}\text { Changes of working } \\
\text { practices }\end{array}$ & S110 & S210 & S310 & S410 \\
\hline$i=11$ & $\begin{array}{l}\text { Max. allowable } \\
\text { interruption }\end{array}$ & S111 & S211 & S311 & S411 \\
\hline$i=12$ & $\begin{array}{l}\text { Develop warning } \\
\text { system }\end{array}$ & S112 & S212 & S312 & S412 \\
\hline$i=13$ & Implication monitoring & $\mathrm{S} 113$ & S213 & S313 & S413 \\
\hline$i=14$ & Insurance arrangement & S114 & S214 & S314 & S414 \\
\hline$i=15$ & $\begin{array}{l}\text { Re-evaluating } \\
\text { contingency plan }\end{array}$ & S115 & S215 & S315 & S415 \\
\hline$i=16$ & $\begin{array}{l}\text { Network and procedure } \\
\text { redesign }\end{array}$ & S116 & S216 & S316 & S416 \\
\hline
\end{tabular}

Note: $\mathrm{J}=1$ (Delay); $\mathrm{J}=2$ (Deviation); $\mathrm{J}=3$ (Stop) and $\mathrm{J}=4$ (Loss)

\section{MODELLING OF DISRUPTION MANAGEMENT ASSESSMENT}

The objective of modelling the disruption management process is to determine an optimal disruption strategy for events that recurrently and severely impact maritime services and the WSC process. The roles of the senior managers of WSC entities surveyed during the maritime disruptions study provided input for a disruption management assessment. The subjective perspectives of respondents related to the flexibility factors and real-time responses to maritime disruptions have also been appraised in terms of total costs and time.

The maritime disruptions occurring in the Australian-Indonesian WSC vary in both frequency and severity, from high probability and low consequence disruptions to low probability and high consequence disruptions. To account for this variability, a maritime disruption management (MDM) framework is proposed, incorporating a WSC simulation with available data and specific judgments by quantifying disruption levels and estimating the contribution of situational attributes to MDM.

In estimating the level of maritime disruptive risks quantitatively, three questions need to be considered: i) What are the driving factors of MDM events?; ii) How likely are they to occur?; and iii) If they do occur, what are the consequences? To answer these questions, the scenarios listed in Table 2 will be used. Let $s_{i}$ be the $i^{\text {th }}$ scenario, and $p_{i}$ and $x_{i}$ be its probability and consequence (either in costs and time), respectively. In the case of MDM, disruption risks can be defined as unexpected events that can be driven from instigating, interdependent, and decision maker factors resulting in four progressive factors, i.e. delays, deviations, stoppages, and loss of maritime services. The risk level of a maritime disruption scenario $i$ is defined as follows:

$$
R_{i}=p_{i}\left(x_{i}\right),
$$

where $p_{i}$ is a disruption probability and $x_{i}$ a consequence impact.

A Markov chain of a WSC has a set of states in the WSC process denoted as $S=\left(s_{1}, s_{2}, \ldots, s_{n}\right)$. The process starts in one of these states and moves successively from one state (such as a farmer) to another (until the final consumers). Each move is called a step. If the WSC is currently in state $s_{i}$, then it moves to state $s_{j}$ in the next step at probability $p_{i j}$. This probability does not depend upon which state the chain was in before the current state. The probabilities $p_{i j}$ are called transition probabilities (TP). The probability of remaining in the same state $i$ is $p_{i}$. An initial probability distribution, defined as $S$, specifies the starting state. In general, if a Markov chain has $r$ states, then the following general theorem is easy to prove by using the above observation and induction.

For a Markov Decision Process (MDP) defined by a finite set of states, $S$, a finite set of actions, $A$, and a transition function, $T: S \times A \times S^{\prime} \rightarrow[0,1]$, 
where $T\left(s, a, s^{\prime}\right)=\operatorname{Pr}\left(s^{\prime} \mid s, a\right), \quad$ where $\operatorname{Pr}\left(s^{\prime} \mid s, a\right) \equiv$ $\equiv \operatorname{Pr}\left(s_{t+1}=s^{\prime} \mid s_{t}=s, a_{t}=a\right)$ is the probability that action $a$ in state $s$ at time $t$ will lead to state $s^{\prime}$ at time $t+1$. A reward function $R$ can also be defined as $T: S \times A \rightarrow \mathfrak{R}^{+}$where $\mathfrak{R}^{+}$is the set of positive real numbers. In addition, a disruption management policy is a function $\pi: S \rightarrow A$ and its expectation as expected cumulative reward value function $S: V^{\pi} \rightarrow \mathfrak{R}$, where $\mathfrak{R}$ is the set of real numbers.

The transition function as defined in a MDP is Markovian, i.e. the probability of reaching the next state depends only on the current state and action, and not on the history of earlier states. Inclusion of the transition function allows MDPs to model and reason with non-deterministic (uncertain) actions. Furthermore, the horizon may be either finite or infinite. If a MDP is solved over a finite horizon, then the resulting policy is non-stationary, since the best action to perform may depend on the remaining time. If the horizon is infinite, then the resulting policy is stationary.

The four methods of MDM can be implemented for one particular WSC facing one maritime disruptive event both to reduce the likelihood of occurrence of a primary disruptive event, and to lower maritime risk after being in a normal (initial) stage, $\mu_{0}$. To depict the different approaches of MDM measures and its processes, a diagram of MDM formalism is used in disruption management assessment and is shown in Fig. 2.

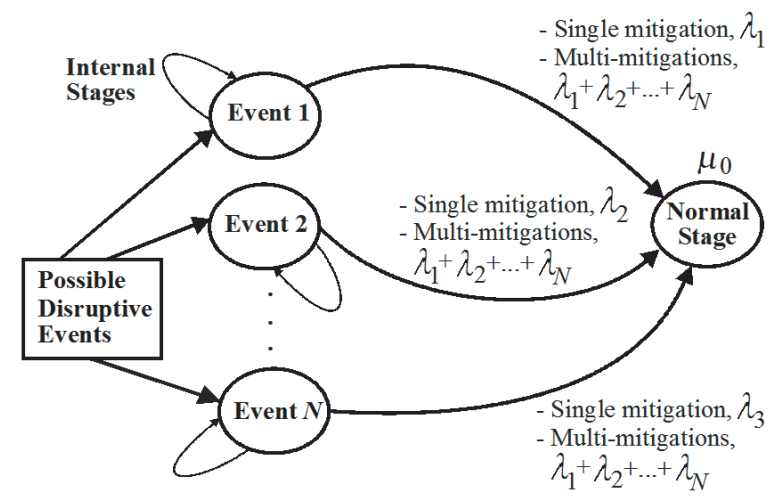

Fig. 2. MDP from disruptive events to normal state

Fig. 3 shows the sequence of MDM events and the process from normal (initial) state to their possible consequences. MDM measures denoted by $(\lambda)$ that reduce the probability of entering a disruptive stage are referred to as single or multi-disruption scenarios. Maritime stages such as port and shipping operations have more than one probable disruptive event (from 1 to $N$ ), which may occur from a normal state to failure mode $(\lambda)$ and may be recovered again due to responses or proper MDM strategies.

$\left[\begin{array}{cccccccccccccc}P_{11} & P_{12} & P_{13} & 0 & 0 & 0 & 0 & 0 & 0 & 0 & 0 & 0 & 0 & 0 \\ P_{21} & P_{22} & P_{23} & 0 & 0 & 0 & 0 & 0 & 0 & 0 & 0 & 0 & 0 & 0 \\ P_{31} & P_{32} & P_{33} & P_{34} & P_{35} & 0 & 0 & 0 & 0 & 0 & 0 & 0 & 0 & 0 \\ 0 & 0 & P_{43} & 0 & P_{45} & 0 & 0 & 0 & 0 & 0 & P_{411} & 0 & 0 & 0 \\ 0 & 0 & P_{53} & P_{54} & 0 & P_{56} & 0 & 0 & 0 & 0 & 0 & 0 & 0 & 0 \\ 0 & 0 & 0 & 0 & P_{65} & P_{66} & P_{67} & 0 & 0 & 0 & 0 & 0 & 0 & 0 \\ 0 & 0 & 0 & 0 & 0 & P_{76} & P_{77} & P_{78} & 0 & 0 & 0 & 0 & 0 & 0 \\ 0 & 0 & 0 & 0 & 0 & P_{86} & P_{87} & P_{88} & P_{89} & P_{810} & 0 & 0 & 0 & 0 \\ 0 & 0 & 0 & 0 & 0 & 0 & 0 & P_{98} & P_{99} & P_{910} & 0 & 0 & 0 & 0 \\ 0 & 0 & 0 & 0 & 0 & 0 & 0 & P_{108} & 0 & 0 & P_{1011} & 0 & 0 & 0 \\ 0 & 0 & 0 & 0 & 0 & 0 & 0 & 0 & 0 & P_{1110} & 0 & P_{1112} & 0 & 0 \\ 0 & 0 & 0 & 0 & 0 & 0 & 0 & 0 & 0 & 0 & P_{1211} & 0 & P_{1213} & 0 \\ 0 & 0 & 0 & 0 & 0 & 0 & 0 & 0 & 0 & 0 & 0 & P_{1312} & 0 & P_{1314} \\ 0 & 0 & 0 & 0 & 0 & 0 & 0 & 0 & 0 & 0 & 0 & 0 & P_{1413} & P_{1414}\end{array}\right]$

Fig. 3. Markov transition matrix in the WSC

A MDM framework can help manage the disruptive events as a single strategy $\left(\lambda_{1}\right)$ or multidisruption management strategy $\left(\lambda_{1}+\lambda_{2}+\ldots+\lambda_{N}\right)$. With analysis of the relevant data, the initial probability vector is calculated as:

$$
V_{j i}=X_{i} D M_{j i},
$$

where $V_{j i}$ is a strategy value index for type $j$ disruptive event for scenario $i ; X_{i}$ probability of occurrence of scenario $i ; D M_{j i}$ type managed consequences of type $j$ related to the scenario $i$.

The mitigation functions are combined to simplify the evaluation of mitigation measures that typically couple detection and recovery functions. Each decision node has a set of conditional probabilities that describe the probability of occurrence of each branch, conditional upon the previous states. The overall likelihood of each outcome is determined by multiplying conditional probabilities through the branch, and the risk level is aggregated along potential consequences in different branches as shown in Eq. (2).

If, in addition, $R_{i j}$ is denoted as the reward corresponding to the transition from stage $i$ to stage $j$, then:

$$
V_{i}=\sum_{j=1}^{N} p_{i j}^{x_{i}}\left(R_{i j}+\beta v_{j}\right) \quad \text { for } \quad i=1, \ldots, N,
$$

where the $V_{i}$ is the value of each disruption strategy at stage $i[12]$.

Note that the above formula can be written as:

$$
V_{i}=\beta \sum_{j=1}^{N} p_{i j}^{x_{i}} v_{j}+\sum_{j=1}^{N} p_{i j}^{x_{i}} R_{i j} \quad \text { for } \quad i=1, \ldots, N
$$


If we denote by $q_{i}^{x_{i}}$ the expected reward for the next transition if the current stage is $i$, then $q_{i}^{x_{i}}=\sum_{j=1}^{N} p_{i j}^{x_{i}} R_{i j}$. Therefore, Eq. (3) becomes:

$$
V_{i}=\beta \sum_{j=1}^{N} p_{i j}^{x_{i}} v_{j}+q_{i}^{x_{i}} \quad \text { for } \quad i=1, \ldots, N .
$$

Managed consequences are evaluated from the potential consequence that is mitigated by the susceptibility and coping capacity of the strategy. The consequences of MDM $j$ relative to the scenario $i\left(D_{j i}\right)$, which is calculated through the Eq. (4), is the sum of all consequences referred to as the intensity threshold value $m$. $V_{j i m}$ is the vulnerability related to intensity $m$ of the $j$ type of consequence and related to the scenario $i, D X_{j i m}$ is the potential consequence type $j$ related to scenario $i$ to consequences $j$ and to intensity $m$ [8] and [12].

$$
D M_{j, i}=\sum_{m}\left(D X_{j, i, m} \cdot V_{j, i, m}\right) .
$$

\subsection{Transition States of WSC}

The detailed interaction of 14 entities (as discussed in Section 3.1) upstream and downstream in the WSC including the disruption strategy options is explained by Fig. 3. Maritime stages such as port and shipping operations have more than one probable disruptive event (from 1 to $N$ ), which may occur from one state to another, including strategies that are also considered as transition probabilistic states $(\lambda)$ and may recover again to a normal state due to responses or MDM strategies.

\subsection{Multi-State Scenarios of MDM}

Let $P_{C}(t)$ be the state probability of $X(t)$ at time $t$, so the probability of event at time $t$ can be defined as:

$$
p_{c}(t)=P[X(t) \geq C] \text { where } C \in X,
$$

where $C$ is an acceptable level of costs or time. The following system of differential equations for finding the four states' probabilities (normal, delay, deviation, and loss of service) $p_{t}(t)$ for the Markov process can be written as:

$$
\frac{d p_{i}(t)}{d t}=\sum_{j=1}^{v} p_{j}(t) \lambda_{j i}(t)-p_{i}(t) \sum_{j=1}^{v} \lambda_{i j}(t) .
$$

These four states or probability levels as shown in Fig. 4, where $\lambda_{i j}$ is the TP from stage of disruption $i$ to stage of disruption $j$, can be explained in detail as follows; $\lambda_{32}$ the TP from stage 3 to stage $2 ; \lambda_{31}$ the TP from stage 3 to stage $1 ; \lambda_{30}$ the TP from stage 3 to stage $0 ; \lambda_{21}$ the TP from stage 2 to stage $1 ; \lambda_{20}$ the TP from stage 2 to stage $0 ; \lambda_{10}$ the TP from stage 1 to stage 0 and $\mu$ the TP from state 0 to state 3 .

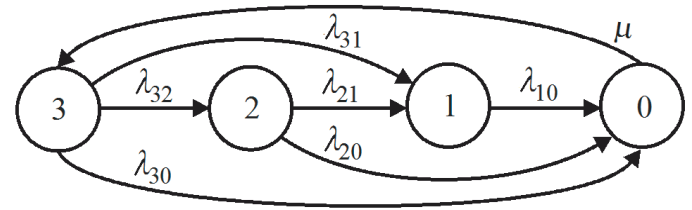

Fig. 4. Maritime disruption stages and scenario

The probabilities of internal stages for each risk event are further approached by using four different MDM stages; these are indicated by states 3, 2, 1 and 0 . A description of each stage is as follows: Stage3: ensuring the normal level of the maritime service availability as planned; Stage 2: the occurrence of delays along maritime services, which creates a less efficient level of service performance; Stage 1: the events of deviations as the results of further divergences of maritime services; Stage 0: the conditions in which disruptions occur due to variable factors that result in various maritime services being unavailable.

These four stages, as part of the Markov chain process, can also be defined as the transitions of maritime disruptions of which the value will depend on the combinations of actions. Assume that the probability functions for the maritime disruptive stages that are defined as states 3,2,1 and 0 for any operational period $t$ that is continuously changing with $t$ are $F_{3}(t), F_{2}(t), F_{1}(t), F_{0}(t)$ respectively, where:

$$
F_{3}(t)+F_{2}(t)+F_{1}(t)+F_{0}(t)=1 .
$$

Thus, to find the probability function for each stage, a system of differential equations based on MDP is applied on the assumption that the transition rates are relatively constant and can be estimated from historical records. With reference to these scenarios, each stage may be formulated as:

$$
\begin{aligned}
& d F_{3}(t) / d t=-\left(\lambda_{32}+\lambda_{31}+\lambda_{30}\right) F_{3}(t)+\mu F_{0}(t), \\
& d F_{2}(t) / d t=-\left(\lambda_{21}+\lambda_{20}\right) F_{2}(t)+\lambda_{32} F_{3}(t), \\
& d F_{1}(t) / d t=-\lambda_{10} F_{1}(t)+\lambda_{21} F_{2}(t)+\lambda_{31} F_{3}(t), \\
& d F_{0}(t) / d t=-\mu F_{0}(t)+\lambda_{30} F_{3}(t)+\lambda_{20} F_{2}(t)+\lambda_{10} F_{1}(t) .
\end{aligned}
$$

Therefore, $M(t)$ or total probabilities of some disrupted stages is equal to: 


$$
M(t)=F_{2}(t)+F_{1}(t)+F_{0}(t) .
$$

From Eqs. (8) and (10), it follows that:

$$
F_{3}(t)=1-M(t) .
$$

\subsection{Optimised MDM Strategies}

The assessment framework for MDM strategies provides a preliminary reference to potential disruption management strategies derived from the MDP that meets the objectives and requirements of company disruption responses. However, in this model, it is possible to select the lowest costs or values that may occur for each strategy and the combination of the three disruption strategies taken. To do so, first, the value or the cost $v_{i}$ of each disruption strategy at state $i$ is formulated by the steady-state condition of MDP:

$$
V_{i}^{*}-\beta \sum_{j=1}^{N} p_{i j}^{x_{i}} v_{j}=q_{i}^{x_{i}} \quad \text { for } \quad i=1, \ldots, N,
$$

where $V_{i}^{*}$ is the value or the cost for the policy solution (see Eq. (4)). The process of disruption policy evaluation is initially started by solving the steady state cost equation using $X_{k}$ as is the optimum disruption management policy. If $v_{i}^{*}=v_{i}$ for all $i$, then the calculation process that is finished as $X_{k}$ has been achieved. Otherwise, increase $k$ by 1 and let $v_{i}=v_{i}^{*}$ and do the iteration process of $\left|V_{i}^{*}-v_{i}\right| \leq \varepsilon$, where $\varepsilon=C$ (acceptable cost level). Therefore, the iteration process will stop if the condition of $\left|V_{i}^{*}-v_{i}\right| \leq$ tolerance value is achieved.

In a steady-state condition, the value $v_{i}$ is equal to:

$$
v_{i}=\lim _{k \rightarrow \infty} V_{i}(k) \quad \text { for } \quad i=1, \ldots, N .
$$

Then Eq. (13) becomes:

$$
\begin{gathered}
V_{i}=q_{i}^{x_{i}}+\beta \sum_{j=1}^{N} p_{i j}^{x_{i}} v_{j} \text { or } V_{i}-\beta \sum_{j=1}^{N} p_{i j}^{x_{i}} v_{j}=q_{i}^{x_{i}} \\
\text { for } i=1, \ldots, N .
\end{gathered}
$$

Therefore, the steady-state disruption probability is $\pi_{i}=\lim _{k \rightarrow \infty} \pi_{i}(k)$ and then continued to:

$$
\pi_{i}=\sum_{j=1}^{N} p_{i j}^{x_{i}} \pi_{j} \quad \text { for } \quad i=1, \ldots, N .
$$

As the set of equations has one redundant equation, then:

$$
\sum_{j=1}^{N} p_{i j}^{x_{i}} \pi_{j}-\pi_{i}=0 \quad \text { for } \quad i=1, \ldots, N-1,
$$

where $\sum_{j=1}^{N} \pi_{j}=1$. Recall that: $X_{i}$ is a disruption management policy implemented in disruption stage $i$ where $P_{i} \in A_{i} ; P=\left(X_{1}, X_{2}, \ldots, X_{N}\right)$ disruption management scenario; $V_{i}(n)$ cost value of stage $i$ at period $n, n=0,1,2, \ldots, N ; V(n)$ is $\left\{V_{1}(n), V_{2}(n), \ldots\right.$, $\left.V_{N}(n)\right\}$ as vector of costs; $\pi_{i}(n)$ probabilities of disruption stage $i$ at period $n, n=0,1,2, \ldots, N ;(n)$ is $\left\{\pi_{1}(n), \pi_{2}(n), \ldots, \pi_{N}(n)\right\}$ as a vector of probabilities.

The initial cost of the disruption management policy $n$ in disruption stage $i$ is $V_{i}(n)$. By using the iteration solution, let $k=1$ combined with the value of disruption management costs, then the minimum consequences can be calculated. The management formulation to address the minimum consequences (e.g. costs) at stage $i$ is given here as:

$$
V_{i}^{*}=\min _{x_{i} \in A_{i}}\left\{q_{i}^{x_{i}}+\beta \sum_{j=1}^{N} p_{i j}^{x_{i}} v_{j}\right\} \text { for } \quad i=1, \ldots, N .
$$

where $A_{i}$ is a set of disruption strategy $i^{\text {th }}$ action. From Eq. (16), let the optimum disruption management policy be $X_{k}$ as the disruption management costs for minimisation can be estimated with $V_{i}^{*}$.

\subsection{Algorithm for Optimised Mitigation Scenario}

In Table 3, the algorithm for the optimised mitigation scenario is proposed. The solution method involves the following calculation: given a set of mitigation scenarios, in the first step, the number of entities in the WSC is incorporated into $S$ (line 1) including the four categories of disruption stages and transitions $\lambda$ (line 2) and mitigation scenarios $D_{j i}$ (line 3).

Next, the probability of the mitigation scenario based on the mitigation policy of entities in the chain is applied (line 4). This is what is also assessed in the next algorithm step in order to estimate the probability at time $t$ and acceptable level of costs $C$ (lines 6 and 7). Due to the mitigation scenario taken, then the TP and transition costs can be calculated (lines 10 and 11). The objective level of multi-mitigation scenarios is identified in 13: $V_{i}^{*}$ correspondents to the minimal costs or values among various scenarios within available mitigation scenarios. If $V_{i}^{*}$ is undefined because no contradiction could be obtained (line 14), the level of costs or values is equal to $V_{i}$ represents feasible disruption consequences (line 15). Otherwise, a recursive process is started (lines 16 to 22): $V_{i}^{*}$ is initialised (line 16) before the level of consequence (reward) of a scenario applied is identified (line 
17). For each $i$ scenario of a disruption $j$ (line 18), the steady-state of disruption probability may be estimated (line 19 and 20). The set of all identified feasible scenarios is finally returned as the result of the algorithm (line 23).

Table 3. Algorithm of multi-mitigation scenarios

\begin{tabular}{|c|c|}
\hline Line & Process \\
\hline & $S \leftarrow$ Set up the number of entities in the chain $\left(s_{1}, \ldots, s_{N}\right)$ \\
\hline & $\lambda \leftarrow$ Apply four different stage of disruptions $\left(\lambda_{3}, \lambda_{2}, \lambda_{1}, \lambda_{0}\right)$ \\
\hline & $D_{j i} \leftarrow$ Set up mitigation scenario $i$ with disruption $j$ \\
\hline & $\operatorname{Pr}\left(s^{\prime} \mid s, a\right) \leftarrow$ Include probabilities of each actions \\
\hline & for each $C \in X$, do \\
\hline 6 & $P_{c}(t) \leftarrow P[x(t)>C]$ \\
\hline 7 & $M_{t} \leftarrow F_{2}(t)+F_{1}(t)+F_{0}(t)$ \\
\hline & end for \\
\hline & for each $i$ and $j \in N$, do \\
\hline 10 & $p_{i j} \leftarrow$ Transition probabilities \\
\hline 11 & $D M_{j i} \leftarrow$ Transition costs \\
\hline & end for \\
\hline & $V_{i}^{*} \leftarrow \min \left\{q_{i}^{x_{i}}+\beta \sum_{j=1}^{N} p_{i j}^{x_{i}} v_{j}\right\}$ \\
\hline & If $V_{t}^{*}$ is undefined then \\
\hline & $V_{i}^{*}=\left\{q_{i}^{x_{i}}+\beta \sum_{j=1}^{N} p_{i j}^{x_{i}} v_{j}\right\}$ \\
\hline & else, $V_{i}^{*} \leftarrow \Phi$ \\
\hline & $V_{j i} \leftarrow V\left(X_{i}, D M_{j i}\right), V \in R($ reward $)$ \\
\hline 18 & for each $i=1, \ldots, \mathrm{N}$, do \\
\hline 19 & $\pi_{j} \leftarrow$ probabilities of disruption $j$ at period $n$ \\
\hline 20 & $\pi_{i} \leftarrow \pi\left(P_{i j}, \pi_{j}\right)$ \\
\hline & end for \\
\hline & end if \\
\hline & return $S$ \\
\hline
\end{tabular}

\section{EXPERIMENTAL STRATEGY}

\subsection{Australian-Indonesian Wheat Supply Chain}

On the basis of the previously implemented disruption management strategies, it was determined that a business continuity concept was implemented by wheat chain senior managers in the AustralianIndonesian WSC. In order to complete the disruption management assessment, it is necessary to determine which assumptions can be presented, particularly in unit costs needed, to apply the various strategy options. The assumption is relatively straightforward based on a monthly wheat shipment of one parcel volume of 8,201 tons. This is calculated from the basis of 98,420 tons of wheat shipment in one year from ports on the east coast of Australia to either the Port of Tanjung Priok, Jakarta or Tanjung Emas, Semarang.

In the maritime disruption assessment, attributes contributing to disruption occurrence from stages A to $M$ (as shown in Fig. 5 [12]) are quantified in order to estimate the future risk level.

Therefore, in this study, maritime disruption risks are quantified based on the maritime disruption survey, including professional judgment, elicitation and disruption management assessment of the wheat supply chain in the Australian-Indonesian trade link. The disruption risk at various stages of the wheat supply chain is denoted as $s ; R s$ is calculated based on the snapshot of the traffic in that stage every time a wheat consignment enters it. The orientation of wheat cargo starts from local farmers in Australia and then enters the stages in Indonesia's direction. The observed wheat flow, when entering the stages, first (A) calculates its own contribution to the stages disruption and then may contribute to the geometric mean of disruption value of that stage after being accumulated with other wheat at the same stage.

Table 4 shows the results of the assessment of multi-disruption management scenarios of the study. When mitigating maritime disruptions on the Australian-Indonesian WSC, MDP proposes strategies (in the column of action name) that may be implemented by entities (state name column). State value is a contractual cost required by each entity when a disruption occurs to handle the total wheat shipment (line 15, Table 3). The value is calculated from the total tonnage of monthly wheat shipment $(8,201$ tons) and contractual costs allocated by entities. The value of the contractual costs was collected from the 2009 maritime disruption survey interview of 34 senior managers in the AustralianIndonesian WSC. Final cost is a maximum acceptable cost $(C)$ of all companies (line 6, Table 3). The level of this cost is obtained from the value of state costs and the sensitivity factors ranging from 0.1 to $1 \%$. In this case, $0.5 \%$ is applied. The step value is actually the minimum costs that will be occurred from 14 alternatives of scenarios given (see line 13 to 21 , Table 3). The function of this value depends on action costs, decision value, probabilities, decision index, and discount value of costs applied across a one-year period, i.e. 365 days.

Five policy scenarios are recommended: 1) inventory pooling; 2) postponement delays; 3) containerised shipment; 4) implication monitoring and 5) other chain links. Of these alternatives, containerised shipment (CS) is the most essential 


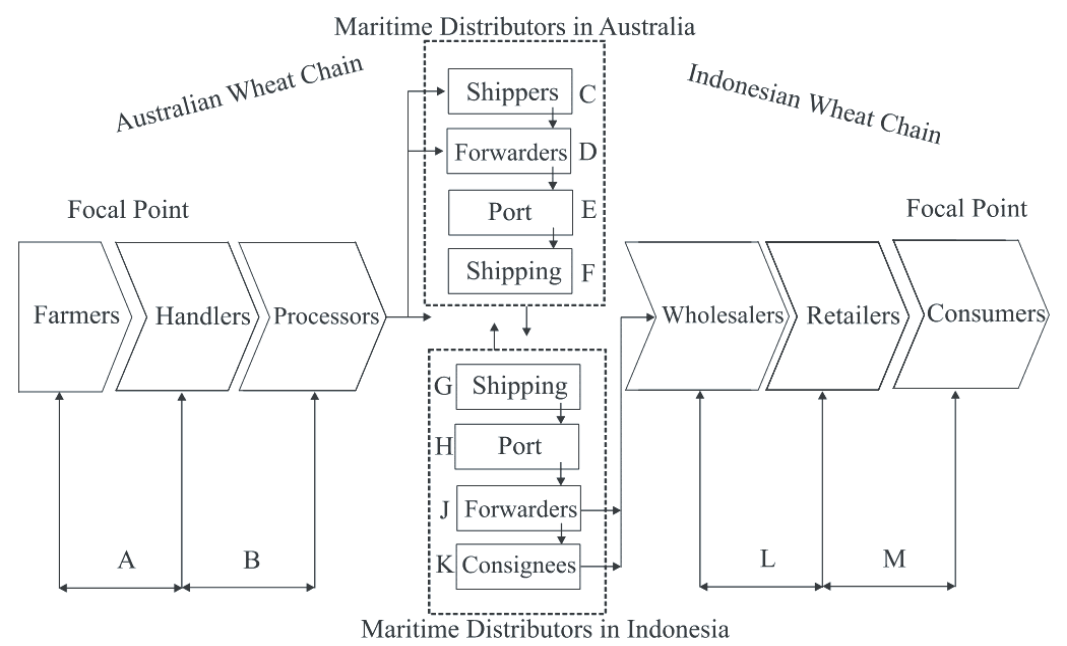

Fig. 5. The wheat supply chain process

Table 4. Multi-mitigation scenarios

\begin{tabular}{|c|c|c|c|c|c|c|c|c|}
\hline \multicolumn{2}{|c|}{ Dynamic programming solver } & \multirow{2}{*}{$\begin{array}{c}\text { Index } \\
1 \\
\end{array}$} & \multirow{2}{*}{$\begin{array}{l}\text { State name } \\
\text { Farmers }\end{array}$} & \multirow{2}{*}{$\begin{array}{c}\begin{array}{c}\text { State cost } \\
\text { [US\$] }\end{array} \\
1,766,596\end{array}$} & \multirow{2}{*}{$\begin{array}{c}\begin{array}{c}\text { Final cost } \\
\text { [US\$] }\end{array} \\
1,775,429\end{array}$} & \multirow{2}{*}{$\begin{array}{c}\begin{array}{c}\text { Step value } \\
\text { [US\$] }\end{array} \\
2,868,913\end{array}$} & \multirow{2}{*}{$\begin{array}{c}\begin{array}{c}\text { Action } \\
\text { name }\end{array} \\
\mathrm{IP} \\
\end{array}$} & \multirow{2}{*}{$\begin{array}{c}\begin{array}{c}\text { Last probability } \\
{[\%]}\end{array} \\
0.215\end{array}$} \\
\hline Type & MDP & & & & & & & \\
\hline Title & $2006-2007$ & 2 & Handlers & 124,995 & 125,620 & $1,227,312$ & $\mathrm{IP}$ & 0.110 \\
\hline States & Min & 3 & Processors & 124,995 & 125,620 & $1,096,495$ & $\mathrm{PD}$ & 0.099 \\
\hline Goal & 14 & 4 & Australian shippers & $1,833,260$ & $1,842,426$ & $2,449,760$ & PD & 0.054 \\
\hline Actions & 14 & 5 & Australian forwarders & $1,999,920$ & $2,009,920$ & $3,102,237$ & IP & 0.042 \\
\hline Action/state & 14 & 6 & Australian. shipping & 999,960 & $1,004,960$ & $1,124,955$ & CS & 0.039 \\
\hline Events & 5 & 7 & Australian ports & 666,640 & 669,973 & $1,768,957$ & $\mathrm{OCL}$ & 0.011 \\
\hline Events/action & 5 & 8 & Indonesian shipping & 708,305 & 711,847 & $1,533,300$ & CS & 0.110 \\
\hline Iteration type & Policy & 9 & Indonesian ports & 374,985 & 376,860 & $1,199,980$ & CS & 0.046 \\
\hline Policy steps & 365 & 10 & Indonesian forwarders & $1,666,600$ & $1,674,993$ & $2,491,595$ & CS & 0.031 \\
\hline Stop Difference & $1.00 \mathrm{E}-06$ & 11 & Consignees & $2,083,250$ & $2,093,666$ & $2,908,245$ & CS & 0.024 \\
\hline Value error & $3.00 \mathrm{E}-06$ & 12 & Wholesalers & $2,124,915$ & $2,135,540$ & $3,024,915$ & IM & 0.004 \\
\hline Probability error & $6.30 \mathrm{E}-09$ & 13 & Retailers & $2,166,580$ & $2,177,413$ & $2,588,897$ & $\mathrm{IP}$ & 0.001 \\
\hline Time measure & Days & 14 & Final consumers & $2,208,245$ & $2,219,286$ & $2,616,562$ & IP & 0.215 \\
\hline
\end{tabular}

Note: Inventory pooling (IP); Postponement delays (PD); Containerised shipment (CS); Other chain links (OCL); Implication monitoring (IM).

scenario as it may generate state and final costs more efficiently, particularly for entities such as maritime service providers. The cost reduction as a reward in applying CS may gain significant maximum step values gained by Australian shipping operators, Indonesian shipping and port operators, including Indonesian forwarders. The MDP also estimates that farmers and final consumers are the entities that may experience a higher likelihood of maritime disruptions of less than $22 \%$ compared to retailers $(0.1 \%)$.

\subsection{Simulation Results}

Reconfiguring other links in the supply chain is recommended to shift shipping services from dry bulk operations to CS. This also consequently requires the use of a container terminal rather than a grain terminal. The outputs of probabilistic levels of each entity from the scenario assessment (see Fig. 6a to c) indicate that farmers and final consumers are entities with the same consequences at the end of the disruption period (for about 365 days). Another issue is that the higher probabilistic level of commercial and operational consequences due to maritime disruptions may severely impact Australian handlers and wheat processors and Indonesian shipping companies. It is estimated that retailers in Indonesia will have no commercial consequences because the risks affecting this entity are likely to be passed on to final consumers. In general, by applying multi-strategy 


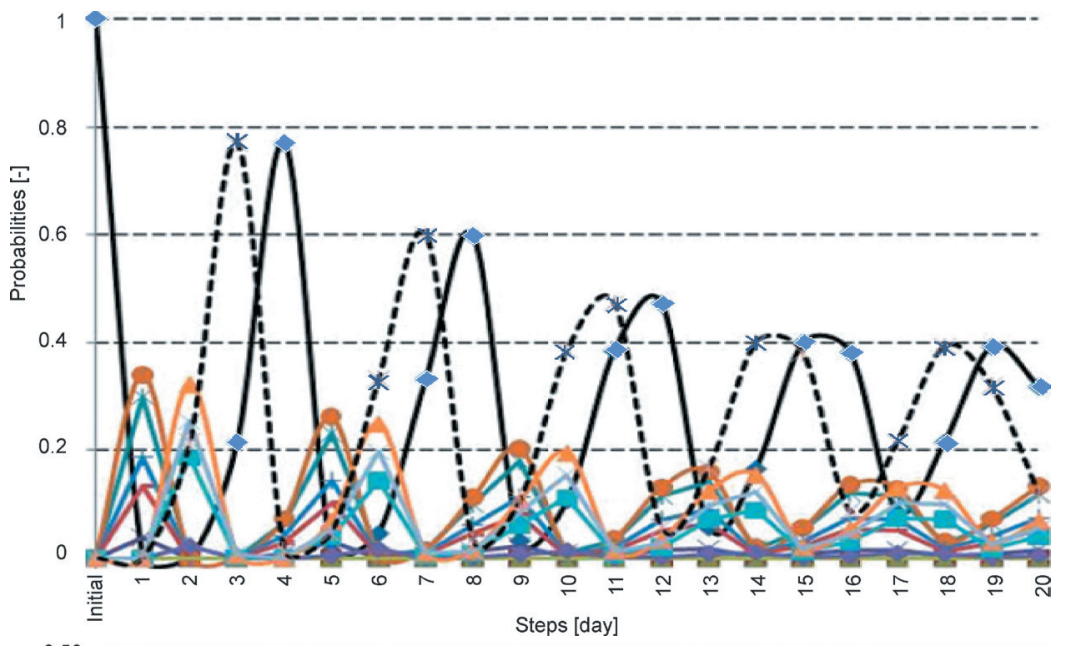

a)

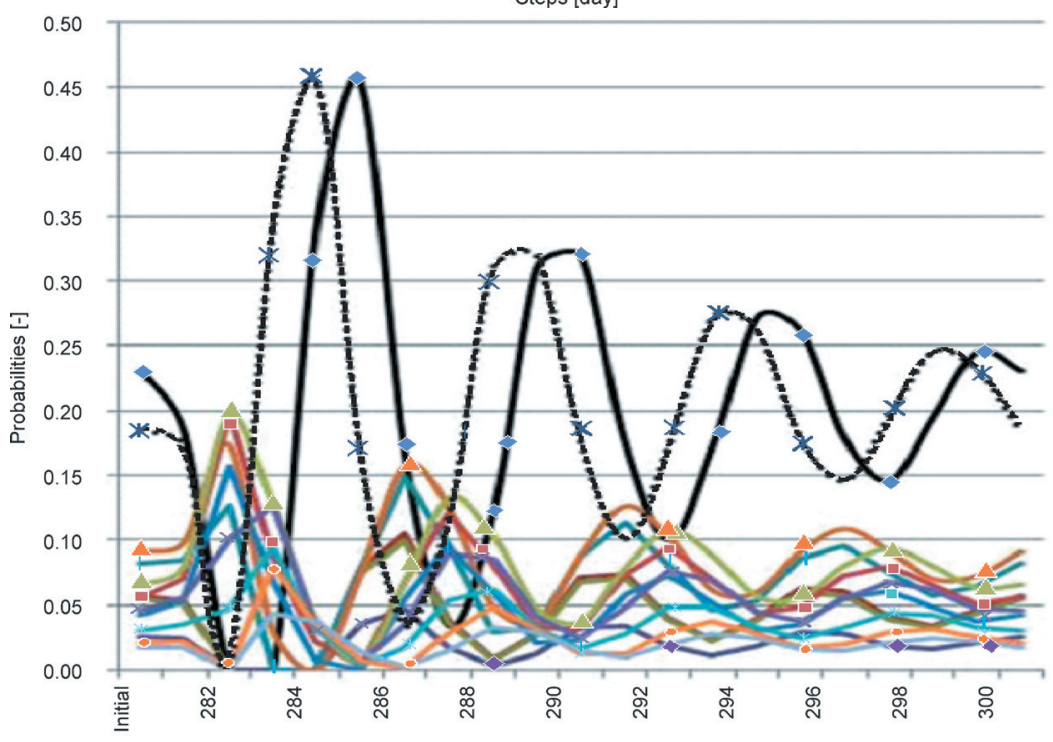

b)

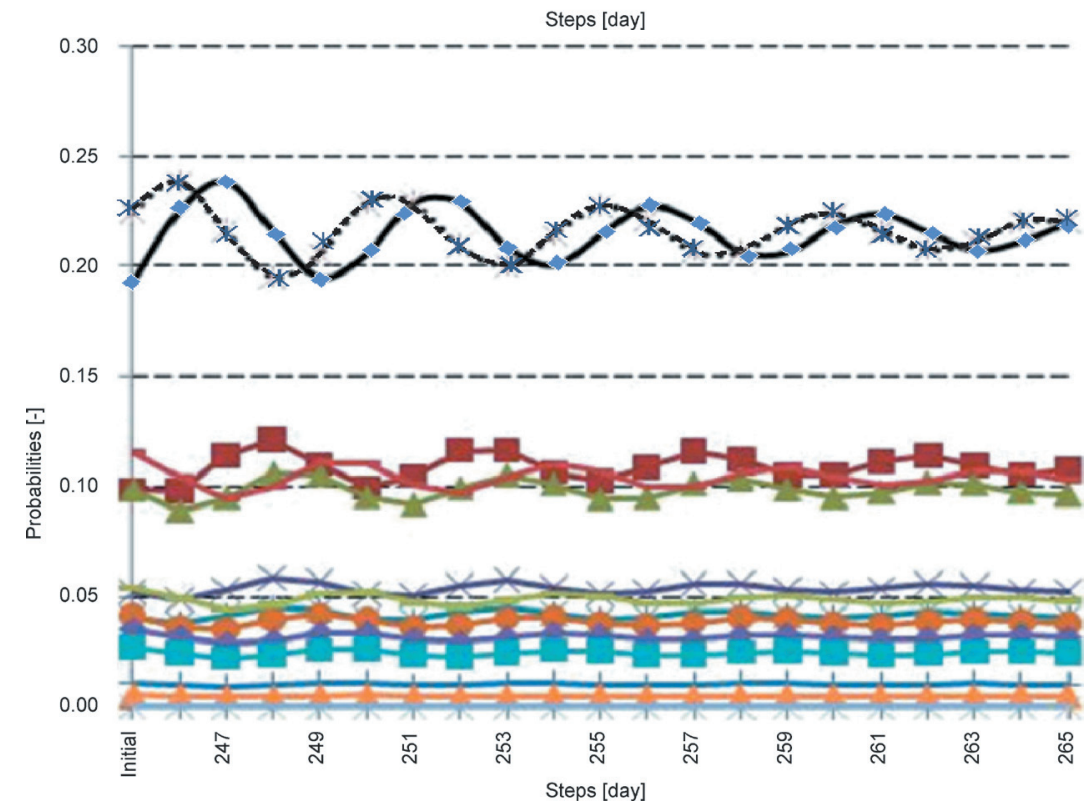

c)

Fig. 6. The transition probabilities of one-year WSC; a) from day 0 to day 20 , b) from initial period to day 300 , c) from initial period to day 365 
scenarios, business entities on the maritime leg may be affected with relatively low levels of risk probabilities ranging from 3 to $5 \%$; farmers and final consumers may experience maritime risk probabilities in the range of 21 to $22 \%$. This is different from handlers and processors who may have 10 to $11 \%$ of maritime disruption risks.

The outputs of TPs of the case are presented for 365 days. From day zero to the $20^{\text {th }}$ day (as shown in Fig. 6a), farmers are estimated to have transition probabilistic levels ranging from 18 to $55 \%$ as an entity in the chain that may experience the highest level of risk consequences. Similarly, handlers and processors in the chain may achieve 18 to $25 \%$ probabilistic levels; processors in Australia and Indonesian shipping companies and wholesalers have a TP level of $0.4 \%$.

If the maritime disruption event is continuing, in the ranges of 21 to 40 and 41 to 60 days, the amplitude of TPs is decreased for all entities (except wholesalers, whose amplitude remains at $0.4 \%$ ) to 18 to $21 \%$ for farmers, and $10 \%$ for handlers, processors and Indonesian shipping companies. After the period of the $60^{\text {th }}$ day, the TPs pattern takes a similar configuration with a relatively constant level of values. Thus, TP outputs from days 341 to 365 have a constant level for all entities (as shown in Fig. 6c). Furthermore, in the constant level of TP, there are three groups of TPs. One is the group of two entities (i.e. farmers and final consumers) that may be clustered in a similar probability value.

In practice, however, entities in the wheat supply chain have various barriers to implementing mitigation strategies due to financial and source limitations. In addition, it was found that entities with good coordination levels along the wheat supply chain may have a mitigation outcome due to its visibility and monitoring capacity in managing maritime disruptions.

\section{CONCLUSIONS}

In this paper, the multi-mitigation strategy modelling of maritime disruptions in a WSC have been investigated. The level of service is proposed to represent the TP of satisfying the farmers and final consumers in the WSC, and it has been formulated as MDP. The application of MDM scenarios using the MDP for maritime disruptions may minimise the consequences of the risks in the containerised WSC. An experimental strategy has been carried out for the model assessment and impact analysis of the confidence parameters in the containerised AustralianIndonesian WSC.

The contribution of the paper is threefold. The first is a new approach that combines the advantages of MDP. An analytical model has been presented and the simulation based on implemented MDM strategies. The second and third contributions are a proposed model and suggestion that containerised WSC are able to generate competitive solutions quickly, even compared with traditional planning approaches that are much more time consuming.

MDM represents not only mitigation responses but also a set of adaptation actions and feedback from the experiences of facing the disruptive events. It can be implemented to rectify both the consequences of disruption impacts and the probability of unwanted internal and external factors that may recurrently and severely change the stability of maritime services in the considered WSC. If the set of indicators could be applied to another territorial situation, the expression of their relevance will need to be discussed with stakeholders of this new region. It is in this context that exploring longer term macro-environmental events, such as the impact of climate change on the WSC may provide further insights into other related adaptation practices that may assist with strengthening the resilience of the WSC. As a recommendation, entities with better mitigation responses and coordination capacity may gain more significant results for their maritime disruption mitigation strategies. Therefore, a coordination factor should be included in the development of any future research model on maritime disruption.

In regards to potential limitations in the study, the participants were self-selected, highly educated, mostly having a supply chain background, and reporting high levels of intentions toward wheat transport as well as the impact of maritime disruptions and its consequences in the wheat trade. It is possible that the managers who volunteered to participate in this research are not representative of the general population. The managers in this study are more likely to be concerned about detailed disruption management strategies that are more likely to be executed in relation to various maritime disruptive events. In any future research, the participation of executives in the real case modelling may contribute to further detailed implementation procedures of maritime disruption risk mitigations. 


\section{REFERENCES}

[1] Kennett, J., Fulton, M., Molder, P., Brooks, H. (1998). Supply chain management: The case of a UK baker preserving the identity of Canadian milling wheat. Supply Chain Management, vol. 3, no. 3, p. 157-166, DOI:10.1108/13598549810230912.

[2] Young, L.M., Hobbs, J.E. (2002). Vertical linkages in agri-food supply chains: changing roles for producers, commodity groups, and government policy. Review of Agricultural Economics, vol. 24, no. 2, p. 428-441, DOI:10.1111/1467-9353.00107.

[3] Wilson, W.W., Carlson, D.C.E., Dahl, B.L. (2004). Logistics and supply chain strategies in grain exporting. Agribusiness, vol. 20, no. 4, p. 449-465, DOI:10.1002/ agr.20026.

[4] Hachicha, W. (2011). A simulation metamodelling based neural networks for lot-sizing problem in MTO sector. International Journal of Simulation Modelling, vol. 10, no. 4, p. 191-203, DOI:10.2507/ IJSIMM10(4)3.188.

[5] Fain, N., Kline, M., Duhovnik, J. (2011). Integrating R\&D and marketing in new product development. Strojniški vestnik - Journal of Mechanical Engineering, vol. 57, no. 7-8, p. 599-609, DOI:10.5545/svjme.2011.004.

[6] Kaljun, J., Dolsak, B. (2012). Improving products' ergonomic value using intelligent decision support system. Strojniški vestnik - Journal of Mechanical Engineering, vol. 58, no. 4, p. 271-280, DOI:10.5545/ sv-jme.2011.193.

[7] Dalfard, V.M., Ranjbar, V. (2012). Multi-projects scheduling with resource constraints and priority rules by the use of simulated annealing algorithm. Technical Gazette, vol. 19, no. 3, p. 493-499.

[8] Yu, G., Qi, X. (2004). Disruption Management. World Scientific Publishing Co. Pte. Ltd, Singapore.

[9] Craighead, C.W., Blackhurst, J., Rungtusanatham, M.J., Handfield, R.B. (2007). The severity of supply chain disruptions: design characteristics and mitigation capabilities. Decision Sciences, vol. 38, no. 1, p. 131156, DOI: 10.1111/j.1540-5915.2007.00151.x.

[10] Paul, J.A., Maloni, M. (2010). Modeling the effects of port disasters. Maritime Economics and Logistics, vol. 12, no. 2, p. 127-146, DOI:10.1057/mel.2010.2.

[11] Merrick, J.R.W., Van-Dorp, J.R., Mazzuchi, T., Har, J.R. (2002). The Prince William sound risk assessment. Interfaces, vol. 32, no. 6, p. 25-40, DOI:10.1287/ inte.32.6.25.6474.

[12] Gurning, S., Cahoon, S. (2011). Analysis of multimitigation scenarios on maritime disruptions. Maritime Policy \& Management, vol. 38, no. 3, p. 251-268, DOI: 10.1080/03088839.2011.572701.

[13] Gurning, S., Cahoon, S., Nguyen, H.O., Achmadi, T. (2011). Mitigating maritime disruptions: Evidence from the Australian-Indonesian wheat supply chain. International Journal of Shipping and Transport Logistics, vol. 3, no. 4, p. 406-429, DOI:10.1504/ IJSTL.2011.041135.

[14] Tomlin, B. (2009). Disruption-management strategies for short life-cycle products. Naval Research Logistics, vol. 56, no. 4, p. 318-347, DOI:10.1002/nav.20344.

[15] Kleindorfer, P.R., Saad, G.H. (2005) Managing disruption risks in supply chains. Production \& Operations Management, vol. 14, no. 1, p. 53-68, DOI:10.1111/j.1937-5956.2005.tb00009.x.

[16] Tang, C.S. (2006). Robust strategies for mitigating supply chain disruptions. International Journal of Logistics Research and Applications, vol. 9, no. 1, p. 33-45, DOI:10.1080/13675560500405584.

[17] Hou, J., Zeng, A.Z., Zhao, L. (2010). Coordination with backup supplier through buy-back contract under supply disruption. Transportation Research E, vol. 46, no. 6, p. 881-895, DOI:10.1016/j.tre.2010.03.004.

[18] Phillips, P.W.B., Smyth, S. (2007). Grounding the management of liabilities in the risk analysis framework. Bulletin of Science Technology Society, vol. 27, no. 4, p. 274-285, DOI:10.1177/0270467607300639.

[19] Skelton, P. (2007). Business continuity and supply chain management: How to manage logistical operations in the event of an interruption or emergency. Journal of Business Continuity \& Emergency Planning, vol. 2, no. 1, p. 13-20.

[20] Haque, C.E., Burton, I. (2004). Adaptation options strategies for hazards and vulnerability mitigation: An international perspective. Mitigation and Adaptation Strategies for Global Change, vol. 10, no. 3, p. 335353, DOI:10.1007/1-4020-4514-X_1.

[21] Howick, S., Eden, C. (2001). The impact of disruption and delay when compressing large projects: Going for incentives?. The Journal of the Operational Research Society, vol. 52, no. 1, p. 26-34.

[22] Carpignano, A., Golia, E., Di Mauro, C., Bouchon, S., Nordvik, J.P. (2009). A methodological approach for the definition of multi-risk maps at regional level: First application. Journal of Risk Research, vol. 12, no. 3-4, p. 513-534, DOI:10.1080/13669870903050269.

[23] Handfield, R.B., McCormack, K. (eds.) (2008). Supply Chain Risk Management: Minimizing Disruptions in Global Sourcing. Auerbach Publications, New York.

[24] Gurning, S. (2011). Maritime disruptions in the Australian-Indonesian wheat supply chain: An analysis of risk assessment and mitigation strategies. $\mathrm{PhD}$ thesis. Australian Maritime College, University of Tasmania, Launceston.

[25] McKelvey, B., Andriani, P. (2010). Avoiding extreme risk before it occurs: A complexity science approach to incubation. Risk Management, vol. 12, no. 1, p. 54-82, DOI:10.1057/rm.2009.14. 